\title{
A revised (PTVA) model for assessing the vulnerability of buildings to tsunami damage
}

\author{
F. Dall'Osso ${ }^{1,4}$, M. Gonella ${ }^{4}$, G. Gabbianelli ${ }^{1}$, G. Withycombe ${ }^{3}$, and D. Dominey-Howes ${ }^{2}$ \\ ${ }^{1}$ CIRSA, Interdepartmental Centre for Environmental Sciences Research, University of Bologna, via S. Alberto 163, 48100 \\ Ravenna, Italy \\ ${ }^{2}$ Australian Tsunami Research Centre and Natural Hazards Research Laboratory, University of New South Wales, Sydney, \\ NSW 2052, Australia \\ ${ }^{3}$ Sydney Coastal Councils Group Inc., Level 14, 456 Kent Street, Sydney, NSW 2001, Australia \\ ${ }^{4}$ Med Ingegneria S.r.l., via P. Zangheri 16, 48100 Ravenna, Italy
}

Received: 21 April 2009 - Revised: 18 August 2009 - Accepted: 24 August 2009 - Published: 9 September 2009

\begin{abstract}
The Papathoma Tsunami Vulnerability Assessment (PTVA) Model (Papathoma, 2003) was developed in the absence of robust, well-constructed and validated building fragility models for assessing the vulnerability of buildings to tsunami. It has proven to be a useful tool for providing assessments of building vulnerability. We present an enhanced version (PTVA-3) of the model that takes account of new understanding of the factors that influence building vulnerability and significantly, introduce the use of the Analytic Hierarchy Process (AHP) for weighting the various attributes in order to limit concerns about subjective ranking of attributes in the original model. We successfully test PTVA3 using building data from Maroubra, Sydney, Australia.
\end{abstract}

\section{Introduction}

Our urban environments are susceptible to damage associated with extreme natural hazards. As populations grow and our cities expand - often in to more hazardous areas, the exposure of our built environment increases. The 2004 Indian Ocean tsunami (2004 IOT) was catastrophic. In some areas (e.g., Banda Aceh city), near complete devastation of the urban landscape occurred.

Abandoning coastal regions affected by hazards such as tsunami is simply not possible for a variety of reasons. Therefore, in order to minimise the losses that will be associated with future tsunami, assessment of building vulnerability from which estimates of probable maximum loss (PML) may be estimated are required. Estimating vulnerability (and

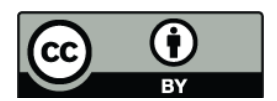

Correspondence to: F. Dall'Osso (filippodallosso@gmail.com)
PML) is important because they are used to determine disaster preparedness and response strategies, to develop appropriate mitigation efforts such as land-use zoning policies, and in the development and application of building codes and regulations.

Recent reports state there is a need for credible fragility models and laboratory data to understand the interaction of tsunami with the built environment (Bernard et al., 2007; Grundy et al., 2005). To our knowledge, no robust, wellconstructed and validated building fragility model for assessing the vulnerability of buildings to tsunami has been developed. Whilst such models are under construction, decision makers (urban planners and emergency managers) are still in need of tools to assist them to make 'first order' assessments of the vulnerabity of structures so that they may begin to establish appropriate risk management strategies. Doing nothing whilst waiting for validated models is not an option.

\subsection{The original Papathoma Tsunami Vulnerability (PTVA) Model}

The Papathoma Tsunami Vulnerability Assessment (PTVA) Model was developed to provide first order assessments of building vulnerability to tsunami and the output of the model assessment is a "Relative Vulnerability Index" $(R V I)$ score for each building (Papathoma, 2003; Papathoma and Dominey-Howes, 2003; Papathoma et al., 2003). The 2004 IOT, although catastrophic, provided a valuable opportunity for the PTVA Model to be tested and evaluated (DomineyHowes and Papathoma, 2007). The attribute fields within the model were well correlated with the damage to building structures experienced during the 2004 IOT (at least where the model was applied). Thus, the model performed very well during a real-life field evaluation. The attributes within the PTVA Model are considered appropriate therefore, for

Published by Copernicus Publications on behalf of the European Geosciences Union. 
use in assessing vulnerability and is useful in the absence of fully validated engineering vulnerability assessment models. The model has recently been applied and tested in the United States (Dominey-Howes et al., 2009).

\subsection{Aim of this work}

The aim of this paper is to revise the original PTVA model to take account of newly published data about attributes that affect building vulnerability (not available when the original model was developed by Papathoma) to tsunami and to introduce a mathematical mechanism (an Analytic Hierarchy Process or AHP) for weighting the various attributes in order to limit concerns about subjective ranking of attributes in the original model. These modifications will enable the development of a second generation PTVA model.

We test the new version of the model (PTVA-3) using building data collected at Maroubra, Sydney. This case is not meant to be extensive, merely indicative to determine that the model works. Dall'Osso et al. (2009) provide a comprehensive application of the model in Sydney. In our work, when we refer to PML, we are referring only to the maximum loss of "buildings" that will be associated with our given scenario. We are fully aware that for many, PML will also include human life, economic loss and so forth.

\section{Structure of the revised model and its attributes}

In this revised PTVA-3 Model, the "Relative Vulnerability Index" (RVI) score of a building is calculated as a weighted sum of two separate elements:

1. the vulnerability of the carrying capacity of the building structure [by which we mean its structural vulnerability] $(S V)$ - associated with the horizontal hydrodynamic force of water flow (the core of the original PTVA model); and

2. the vulnerability of building elements due to their contact with water $(W V)$. This is an entirely new part of the model.

It has been shown that a building with a weak structure (e.g., with a limited number of stories, weak construction material such as timber, with shallow foundations, of poor preservation condition, etc.) can experience extreme damage even though it is only partially submerged. This is because of the hydrodynamic pressure of the flowing water and/or the impact of floating objects such as cars, or boats (Dalrymple, 2005; Warnitchai, 2005). On the other hand, a building with a very resistant structure (e.g., three or more stories, structure made of reinforced concrete, with deep pile foundations, etc.) that is totally submerged by water might loose up to 40$50 \%$ of its value, without sustaining any structural damage (Olivieri and Santoro, 2000).
Consequently, the $R V I$ score of buildings using this revised PTVA-3 Model is calculated as:

$R V I=\frac{2}{3}(S V)+\frac{1}{3}(W V)$

where:

- " $S V$ " is the standardized score for the structural vulnerability, and

_ " $W V "$ is the standardized score for the vulnerability to water intrusion.

Both " $S V$ " and " $W V$ " range between 1 and 5. A weighting coefficient equal to $2 / 3$ has been assigned to $S V$, because heavy damage to the carrying capacity of a structure might reasonably lead to the need for expensive repair works, with costs that might be equal to, or greater than the total value of the building. We assume the contribution to vulnerability from water intrusion is equal to $1 / 3$ and this is consistent with the findings of Olivieri and Santoro (2000).

\subsection{Calculation of structural vulnerability and its at- tributes}

The structural vulnerability " $S V$ " of a building is determined by the:

1. attributes of the building structure $(B v)$;

2. depth of flood water $(E x)$ at the point where the building is located; and

3. the degree of protection (Prot) that is provided to that building by any barriers.

" $S V$ " is calculated as follows:

$S V(1,125)=(B v) \cdot(E x) \cdot($ Prot $)$

where:

- " $B v$ " is a standardized score ranging from 1 (minimum vulnerability) to 5 (maximum vulnerability). " $B v$ " depends on building attributes that influence flood resistance;

- "Prot" is a standardized score for the level of protection that is provided to the building by any barriers. "Prot" ranges between 5 (no protection) and 1 (maximum protection).

- "Ex" is the standardized score for the exposure. Exposure is given by the depth of water expected at the building location. "Ex" ranges between 1 and 5 (1 = minimum water depth, $5=$ maximum water depth). 
Table 1. Original and re-scaled variables used in the calculation of the RVI scores for each building.

\begin{tabular}{|c|c|c|c|c|c|}
\hline$R V I(1-5)$ & $1-1.8$ & $1.8-2.6$ & $2.6-3.4$ & $3.4-4.2$ & $4.2-5$ \\
\hline $\begin{array}{l}\text { Description of } \\
\text { relative vulner- } \\
\text { ability level }\end{array}$ & MINOR & MODERATE & AVERAGE & HIGH & VERY HIGH \\
\hline \multicolumn{6}{|c|}{ Relative Vulnerability Index $(R V I)=(2 / 3) \times(S V)+(1 / 3) \times(W V)($ Eq. 1) } \\
\hline$S V$ (original) & $1-25$ & $25-50$ & $50-75$ & $75-100$ & $100-125$ \\
\hline$S V$ (scaled) & 1 & 2 & 3 & 4 & 5 \\
\hline \multicolumn{6}{|c|}{$S V=(B v) \times(E x) \times($ Prot $)($ Eq. 2$)$} \\
\hline$B v$ (original) & -1 to -0.6 & -0.6 to -0.2 & -0.2 to +0.2 & +0.2 to +0.6 & +0.6 to +1 \\
\hline$B v($ scaled $)$ & 1 & 2 & 3 & 4 & 5 \\
\hline$E x$ (original) & $0-1 \mathrm{~m}$ & $1-2 \mathrm{~m}$ & $2-3 \mathrm{~m}$ & $3-4 \mathrm{~m}$ & $>4 \mathrm{~m}$ \\
\hline$E x($ scaled $)$ & 1 & 2 & 3 & 4 & 5 \\
\hline Prot (original) & 0 to 0.2 & 0.2 to 0.4 & 0.4 to 0.6 & 0.6 to 0.8 & 0.8 to 1 \\
\hline Prot (scaled) & 1 & 2 & 3 & 4 & 5 \\
\hline \multicolumn{6}{|c|}{$W V=($ number of inundated levels $) /($ total number of levels $)($ Eq. 7) } \\
\hline$W V$ (original) & 0 to 0.2 & 0.2 to 0.4 & 0.4 to 0.6 & 0.6 to 0.8 & 0.8 to 1 \\
\hline$W V($ scaled $)$ & 1 & 2 & 3 & 4 & 5 \\
\hline
\end{tabular}

The calculated value of $S V$ (1-125), after being re-scaled to the range (1-5) (Table 1), is inserted in to Eq. (1). It is important to note that in the event that a building is very well protected (with Prot =1), its final " $S V$ " value will be 5 times less than if no protection were present $($ Prot $=5)$. This is consistent with the degree of fragility that Reese et al. (2007) calculated for "shielded" and "exposed" reinforced concrete buildings in Java following the 2005 tsunami.

Our inclusion of specific attributes in " $B v$ " and "Prot" was based on the original PTVA Model, on results from recent post-tsunami field surveys and our expert judgment based on 2004 IOT post-event survey experience.

\subsubsection{Building vulnerability (" $\mathrm{B} v$ ")}

The " $B v$ " score of each building was calculated by considering the contributions made by the following attributes (Table 2):

1. Number of Stories $(s)$ : multi-storey buildings normally need to have more resistant load bearing capability than single storey buildings, because of the larger weight that must be carried by these taller structures.

2. Building Material and Technique of Construction (m): typical Australian buildings have structures that are made of reinforced concrete, a double or a single layer of bricks, or timber. According to available posttsunami field surveys, the most resistant structures were those made of reinforced concrete, followed by double or single bricks. Buildings made of timber were the most vulnerable (Reese et al., 2007; Dominey-Howes and Papathoma, 2007; Rossetto et al., 2006; Ghobarah et al., 2006; Matsutomi et al., 2006; Dalrymple and Kriebel, 2005).

3. Ground Floor Hydrodynamics ( $g$ ): following the 2004 Indian Ocean tsunami, building surveys in Thailand noted that buildings with an open plan ground floor and/or open-breakable accesses (such as doors, windows) decreased the wave impact, allowing the wave to pass through the ground floor. This significantly reduced structural damage (Darlymple and Kriebel, 2005).

4. Foundations $(f)$ : deep foundations can resist more effectively the scouring effect of water flow and can counter the impact of a wave on building walls. During the 2004 tsunami, buildings with shallow or surface spread foundations suffered the heaviest levels of damage (Darlymple and Kriebel, 2005; Warnitchai, 2005; Reese et al., 2007).

5. Shape and Orientation of the building footprint (so): after the 2004 tsunami it was clear from several field surveys that buildings having specific shapes (e.g., hexagonal, triangular, rounded, etc.) suffered lighter damage than long rectangular or "L" shaped buildings whose 
Table 2. The attributes (and their values) influencing the structural vulnerability of a building " $B v$ ". Positive values indicate an increase of the average building vulnerability given by the attribute, while negative values indicate a decrease of the average building vulnerability.

\begin{tabular}{|c|c|c|c|c|c|c|c|}
\hline & -1 & -0.5 & 0 & $(+0.25)$ & +0.5 & $(+0.75)$ & +1 \\
\hline$s$ (number of stories) & more than 5 stories & 4 stories & 3 stories & & 2 stories & & 1 story \\
\hline$m$ (material) & reinforced concrete & & double brick & & single brick & & timber \\
\hline$g$ (ground floor hydrodynamics) & open plan & $\begin{array}{l}\text { open plan and } \\
\text { windows }\end{array}$ & $50 \%$ open plan & & $\begin{array}{l}\text { not open plan, but } \\
\text { many windows }\end{array}$ & & not open plan \\
\hline$f$ (foundation strength) & $\begin{array}{l}\text { deep pile } \\
\text { foundation }\end{array}$ & & $\begin{array}{l}\text { average depth } \\
\text { foundation }\end{array}$ & & & & $\begin{array}{l}\text { shallow } \\
\text { foundation }\end{array}$ \\
\hline so (shape and orientation) & $\begin{array}{l}\text { poor hydro- } \\
\text { dynamic shape }\end{array}$ & & $\begin{array}{l}\text { average hydro- } \\
\text { dynamic shape }\end{array}$ & & & & $\begin{array}{l}\text { high hydro- } \\
\text { dynamic shape }\end{array}$ \\
\hline$m o$ (movable objects) & & & $\begin{array}{l}\text { minimum risk of } \\
\text { being damaged by } \\
\text { movable objects }\end{array}$ & $\begin{array}{l}\text { moderate risk of } \\
\text { being damaged by } \\
\text { movable objects }\end{array}$ & $\begin{array}{l}\text { average risk of } \\
\text { being damaged by } \\
\text { movable objects }\end{array}$ & $\begin{array}{l}\text { high risk of being } \\
\text { damaged by } \\
\text { movable objects }\end{array}$ & $\begin{array}{l}\text { extreme risk of } \\
\text { being damaged by } \\
\text { movable objects }\end{array}$ \\
\hline$p c$ (preservation condition) & very poor & poor & average & & good & & excellent \\
\hline
\end{tabular}

main wall was orientated perpendicular to the direction of flow (Warnitchai, 2005; Dominey Howes and Papathoma, 2007).

6. Movable Objects (mo): during inundation, movable objects (debris, cars, boats and even trucks) will be dragged around by the flowing water and pushed against buildings, causing heavy structural damage (Darlymple and Kriebel, 2005).

7. Preservation Condition ( $p c)$ : buildings which are in a poor state of preservation are generally expected to suffer heavier damage, especially if there are structural failures or deformations.

" $B v$ " attributes must be recorded for each building and a numerical value between -1 to +1 assigned to each (Tables 1 and $2-B v$ (original)). The use of positive and negative values for $B v$ attributes permits the expansion of the overall $B v$ score of buildings to a wider range. This is in line with the approach used by Cutter et al. (2003). Using this approach, we suggest that a building with "average" vulnerability is one that has a "zero" score for each attribute (and which has no protection). Once a score has been assigned to each attribute, an initial value for " $B v$ " (ranging between -1 to +1 ) (Table 2) may be calculated through a weighted sum of all the attributes:

$$
\begin{aligned}
B v(-1,+1) & =w_{1} \cdot s+w_{2} \cdot m+w_{3} \cdot g+w_{4} \cdot f+w_{5} \cdot s o \\
& +w_{6} \cdot m o+w_{7} \cdot p c
\end{aligned}
$$

Where: " $w_{i}$ " is the weighting coefficient of each attribute.

Weights were calculated using the approach described in Sect. 2.3 (they can range between 1 and 100). After scaling to 1 (each weight is divided by the sum of all weights, that is 423), each weight was added to give Eq. (4):

$$
\begin{aligned}
B v(-1,+1) & =\frac{1}{423}(100 \cdot s+80 \cdot m+63 \cdot g \\
& +60 \cdot f+51 \cdot m o+46 \cdot s o+23 \cdot p c)
\end{aligned}
$$

This relation gives as a result, a value of " $B v$ " ranging from -1 to +1 . In order to use " $B v$ " in Eq. (2) it must be rescaled to a range from 1 to 5 (Table $1-B v$ (scaled)).

\subsubsection{The protection factor ("Prot")}

The second element of Eq. (2) is the protection factor "Prot". Factors that affect the protection of a building are shown in Table 3 and described below.

1. The building row (Prot_br): post-tsunami field surveys demonstrated that buildings located in rows further inland were somewhat shielded even when buildings in front of them collapsed (Dominey-Howes and Papathoma, 2007; Reese et al., 2007).

2. The presence of a seawall (Prot_sw): Darlymple and Kriebel (2005) noted that building damage from the 2004 tsunami in Thailand was significantly lower in places protected by seawalls. The design of the seawall was also important. For example, at the north of Patong Beach (Phuket Island), the seawall had a sloped face that essentially created a ramp for the tsunami to run-up across and over. In this case, there appeared to be no protective effect from the seawall to the buildings located landward of the wall.

3. Natural barriers (Prot_nb): natural barriers appear to both reduce velocity and trap debris and heavy floating objects that would otherwise damage buildings (Matsutomi et al., 2006; Olwig et al., 2007; Tanaka et al., 2006). 
Table 3. Scores assigned to the four attributes influencing the level of protection of a building "Prot". Scores close to zero indicate a high protection level, while scores equal to 1 indicate the lowest level of protection.

\begin{tabular}{|c|c|c|c|c|c|}
\hline & 0 & +0.25 & +0.5 & +0.75 & +1 \\
\hline $\begin{array}{l}\text { Prot_br } \\
\text { (building row) }\end{array}$ & $>10$ th & $7-8-9-10$ th & 4-5-6th & 2nd-3rd & $1 \mathrm{st}$ \\
\hline $\begin{array}{l}\text { Prot_nb } \\
\text { (natural barriers) }\end{array}$ & $\begin{array}{l}\text { very high } \\
\text { protection }\end{array}$ & high protection & average protection & $\begin{array}{l}\text { moderate } \\
\text { protection }\end{array}$ & no protection \\
\hline $\begin{array}{l}\text { Prot_sw } \\
\text { (seawall height } \\
\text { and shape) }\end{array}$ & vertical and $>5 \mathrm{~m}$ & $\begin{array}{l}\text { vertical and } \\
3 \text { to } 5 \mathrm{~m}\end{array}$ & $\begin{array}{l}\text { vertical and } \\
1.5 \text { to } 3 \mathrm{~m}\end{array}$ & $\begin{array}{l}\text { vertical and } 0 \text { to } \\
1.5 \mathrm{~m} \mathrm{OR} \text { sloped } \\
\text { and } 1.5 \text { to } 3 \mathrm{~m}\end{array}$ & $\begin{array}{l}\text { sloped and } 0 \text { to } \\
1.5 \mathrm{~m} \mathrm{OR} \text { no } \\
\text { seawall }\end{array}$ \\
\hline $\begin{array}{l}\text { Prot_w } \\
\text { (brick wall around } \\
\text { building) }\end{array}$ & $\begin{array}{l}\text { height of the wall is } \\
\text { from } 80 \% \text { to } 100 \% \\
\text { of the water depth }\end{array}$ & $\begin{array}{l}\text { height of the wall is } \\
\text { from } 60 \% \text { to } 80 \% \\
\text { of the water depth }\end{array}$ & $\begin{array}{l}\text { height of the wall is } \\
\text { from } 40 \% \text { to } 60 \% \\
\text { of the water depth }\end{array}$ & $\begin{array}{l}\text { height of the wall is } \\
\text { from } 20 \% \text { to } 40 \% \\
\text { of the water depth }\end{array}$ & $\begin{array}{l}\text { height of the wall is } \\
\text { from } 0 \% \text { to } 20 \% \text { of } \\
\text { the water depth }\end{array}$ \\
\hline
\end{tabular}

4. Presence of a brick wall around the building (Prot_w): individual walls located around building structures (such as garden walls) although not specifically constructed to provide protection from flooding, do offer some protection from flood inundation (DomineyHowes and Papthoma, 2007).

In the case of "Prot", the score range is from 0 (maximum protection) to +1 (no protection), because the presence of protection can only decrease the average vulnerability of buildings. Assigned scores are shown in Table 3.

An initial numerical value of "Prot" (ranging between 0 and 1) was obtained though a weighted sum of all protection factor scores. Thus:

$\operatorname{Prot}(0,+1)=w_{1} \cdot$ Prot_br $+w_{2} \cdot$ Prot_sw $+w_{3} \cdot$ Prot_nb $+w_{4} \cdot$ Prot_w

Again, weights were calculated using the approach described at Sect. 2.3 (they can range between 1 and 100). After scaling to 1 (each weight is divided by the sum of all weights, that is 301), each weight was added to give Eq. (6):

$$
\begin{aligned}
\operatorname{Prot}(0,+1) & =\frac{1}{301}[100 \cdot \cdot(\text { Prot_br })+73 \cdot(\text { Prot_nb }) \\
& +73 \cdot(\text { Prot_sw })+55 \cdot(\text { Prot_w })]
\end{aligned}
$$

This relation gives as a result a value of "Prot" ranging from 0 to 1 (Table 1 - Prot (original)). In order to use "Prot" in Eq. (2) it must be rescaled to a range from 1 to 5 (Table 1 Prot (scaled)).

\subsubsection{The Exposure ("Ex")}

The third and final part of Eq. (2) is exposure " $E x$ " that relates to the depth of the water flow at the point where the building is located. The level of structural damage is expected to increase with water depth because the pressure applied to the building and flow velocity are direct functions of flow depth (Fritz et al., 2006). Scores have been given to " $E x$ " according to Table $1-E x$ (original) and are then rescaled (Table $1-E x$ (scaled)).

\subsection{Calculation of vulnerability to water intrusion}

Once the floor of a building has been inundated, all the parts of that floor that are damaged by the water (including, in some cases, the adjoining walls) will need to be repaired or replaced. Thus, the overall vulnerability of a building to contact with water is clearly dependent on the number of floors that are inundated in each building (including the basement).

Consequently, we assign to " $W V$ " a score that indicates what percentage of the floors of a building will be inundated (Table $3-W V$ (original)). Hence, for each building:

$W V(0,+1)=\frac{(\text { number of inundated levels })}{(\text { total number of levels })}$

The value of " $W V$ " to be inserted in Eq. (1) has been obtained by re-scaling " $W V(0,1)$ " to a range between 1 and 5 and is given in Table $1-W V$ (scaled).

Once " $S V$ " and " $W V$ " are obtained, the 'Relative Vulnerability Index' $(R V I)$ score for each building is calculated using Eq. (1). The range of $R V I$ values is rescaled to 5 equal classes and the final description of the RVI classes is given in Table 1.

\subsection{Weighting of the attributes}

It is obvious that the " $B v$ " attributes cannot have an equal effect on the vulnerability of a building. For example, the number of stories as well as the construction material, are much more important than the preservation condition, or the shape-orientation of the building. A concern associated with the original PTVA Model of Papathoma (2003) has always been whether the ranking of the attributes was appropriate. 
It must be clearly understood however, that in the original model architecture, the attributes were weighted using expert judgments developed from a review of the best available published literature dealing with building damage from tsunami.

To address concerns of subjective weighting of the attributes however, weights have been recalculated here via pair-wise matches between each of the attributes. Comparisons between attributes were undertaken using an evaluation matrix by means of the M-Macbeth software, a specially designed platform for multi criteria analysis and decisionmaking (Bana e Costa et al., 2004; Bana e Costa and Chagas, 2004).

MACBETH is the acronym of "Measuring Attractiveness through a Category Based Evaluation TecHnique", which is the goal of the Analytic Hierarchy Process. Through the use of the M-Macbeth software the difference of importance between two factors can be qualitatively evaluated using the following semantic categories: "extreme", "very strong", "strong", "moderate", "weak", "very weak" and "no difference".

In the revised PTVA-3 Model, M-Macbeth has been used only for performing pair-wise comparisons between attributes affecting the structural vulnerability of buildings, as well as their level of protection. Every single attribute has been compared with all the others, both for " $B v$ " and "Prot". A total of 21 comparisons for " $B v$ " and 7 for "Prot" were undertaken.

Based upon published results of post-tsunami field surveys, personal expertise and professional judgment, we undertook pair-wise comparisons between the attributes and evaluated their difference in importance using Macbeth semantic cathegories. Every single comparison is described and discussed in Dall'Osso and Dominey-Howes (2009). While we were performing the pair-wise matches, MMacbeth was automatically looking for inconsistent judgments. When identified, inconsistencies were removed. Once all the comparisons were completed, the software calculated the relative weight of each attribute. The same process was repeated for the protection factors. Using this approach, weights for different attributes have been calculated, and the unavoidable subjective component of the decision making process has been reduced to a minimum.

\section{Testing the method at Maroubra, Sydney}

In order to test the effectiveness of our revised PTVA-3 Model, we applied the vulnerability assessment tool to the area of Maroubra, SE Sydney, Australia. As the design inundation scenario we assumed a hypothetical tsunami event that achieves a run-up of $+5 \mathrm{~m}$ a.s.l., occuring during the peak of the maximum high tide ( $+2 \mathrm{~m}$ a.s.l.). This is a purely "deterministic" scenario, since "probabilistic" approaches for estimating tsunami inundation for the study area have not yet been developed.
We used a Geographic Information System (GIS) in which to run the model analysis and present the results in map form. In order to build the GIS and run the model, the following data were obtained:

- A recent (2008) geo-referenced and ortho-rectified aerial image of Maroubra that was used as the geographical base of the study. The aerial images were useful when it was necessary to manually digitize building vector files and for obtaining specific building features needed by the model (e.g., shape and orientation of the building footprint, building row, the presence of movable objects and protection provided by natural barriers). These images were provided by Randwick local government authority;

- A Lidar Digital Elevation Model (DEM). The DEM was used to calculate the water depth above the ground surface by subtracting the ground elevation from the horizontal flood surface at specific grid (building) points.

- Attribute data for each building. The data included all factors required by Eq. (1). These datasets were not available from Randwick council and so we undertook field surveys to collect these data building-by-building; and

- A shapefile of polygons representing building footprints. Shapefiles were manually digitized by us. Building attribute data was then entered in to the GIS database for each building file.

Figure 1 displays the area of Maroubra that would be inundated by a tsunami achieving a run-up of $+5 \mathrm{~m}$ a.s.l., during the maximum high tide. A relatively small area of Maroubra would be inundated by the tsunami in this scenario ( $27 \mathrm{ha}$ ). The deepest inundation is confined to the beach strip running northeast-southwest. Water would be able to penetrate inland from the south, northwards up in to the Arthur Bryne Reserve. The largest area inundated by the tsunami in this scenario lies northwest of the northern end of Maroubra Beach and includes several blocks of commercial and residential structures. Water flow depth would be no greater than $3 \mathrm{~m}$ above the ground surface throughout much of this area.

A total of 96 buildings of various types would be flooded by the tsunami in this scenario. The RVI score of each building is also displayed in Fig. 1. It can be seen that just four individual buildings are classified as having a "High" RVI score. No buildings are classified as "Very High".

The large building at the intersection of Mons and Fenton Avenue is the Maroubra Ambulance Station. It is one of the buildings assessed as having a "High" RVI, even though its successful operation would be crucial in the event of a real tsunami emergency. In light of this study, Randwick Council might consider options for reducing the structural vulnerability of the ambulance station and could even consider relocating it outside the inundation zone. 


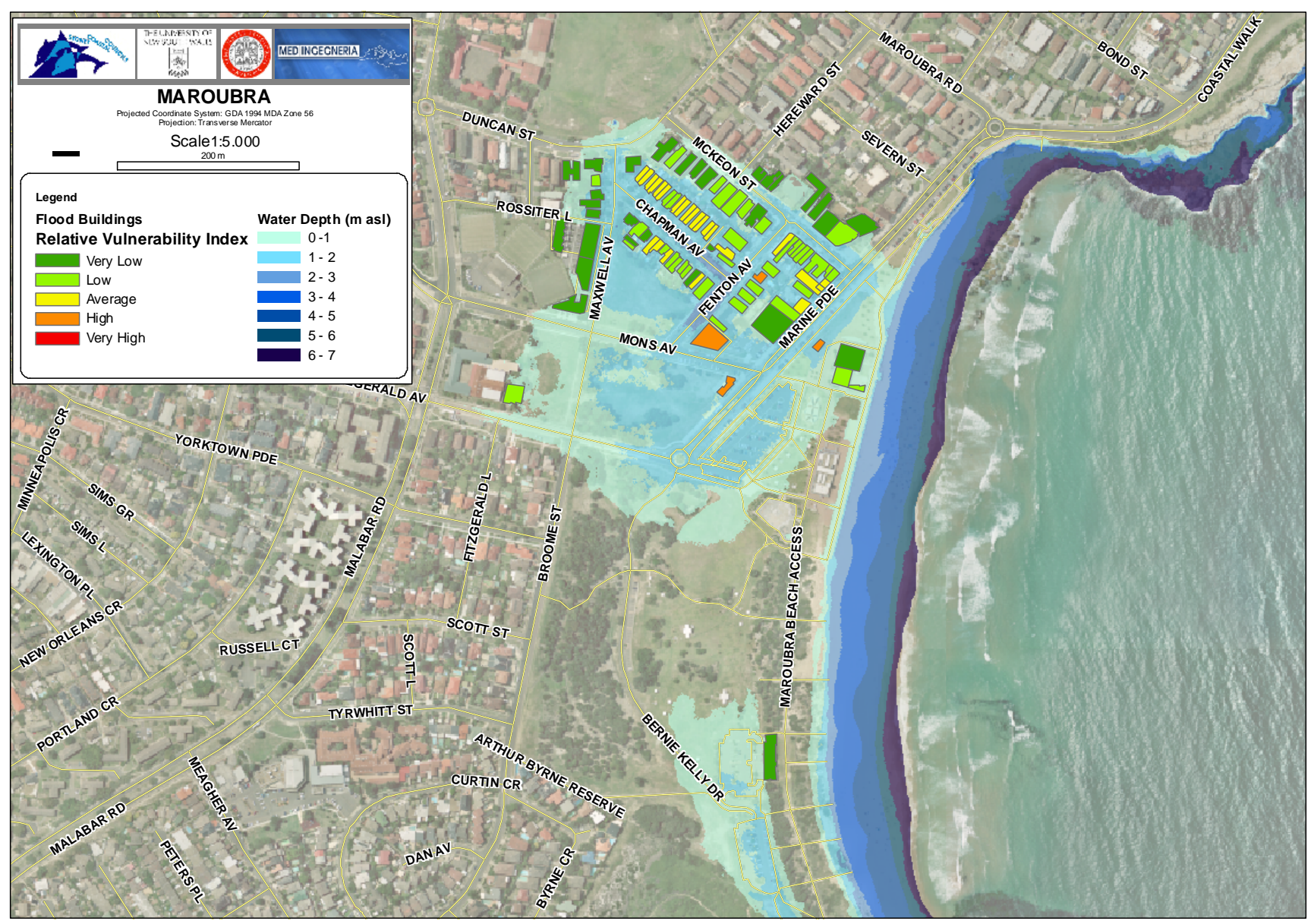

Fig. 1. Map showing the area of Maroubra, Sydney inundated by a tsunami achieving a flood run-up of $+5 \mathrm{~m}$ a.s.l. Also shown are the buildings that would be inundated (and damaged) by the tsunami. Specifically, the revised PTVA-3 model has been used to calculate the "Relative Vulnerability Index" $(R V I)$ scores for each of the buildings located within the inundation zone.

\section{Conclusions}

The original PTVA Model (Papathoma, 2003) is a useful tool for providing initial assessments of the vulnerability of buildings. We have improved the PTVA Model in two ways. First, we have introduced an entirely new set of attributes that are now known to affect the vulnerability of buildings to damage in tsunami - those related to water intrusion. Second, we introduced a multi-criteria approach to the assessment of building vulnerability. This approach based on pairwise comparisons between attributes - is a method typically used in multi-criteria analysis and Analytic Hierarchy Process (Saaty, 1986). Thanks to this technique, the contribution made by separate attributes to the overall structural vulnerability of a building can be compared via a rigorous mathematical approach. This avoids biases and reduces to a minimum the inevitable subjective component of every decisionmaking process and a concern associated with the original PTVA Model.
We have tested the revised method (PTVA-3) at Maroubra, Sydney and it has provided a clear approach for assessing the vulnerability of buildings to tsunami in the absence of fully validated fragility models.

Outputs of the PTVA-3 include thematic vulnerability maps displaying the Relative Vulnerability Index of every single building. Vulnerability maps may be used by Local Government Authorities (LGAs) for future urban planning, to develop emergency plans and decide whether further prevention measures should be considered. Insurance companies may be interested in the results.

The PTVA-3 model is based on the use of GIS. GIS is a very common and easy-to-use approach to the management of spatial datasets. Once data about building attributes and the $R V I$ of buildings are entered into a GIS, they can be retrieved, modified and kept up to date very easily. Also, GIS facilitates the display of results in many different ways, which can suit the needs of different stakeholders and decision makers (e.g., LGAs, urban planners, emergency services, insurance companies). 
We recommend the application of the PTVA-3 model elsewhere, although it must be recognised that some limitations are associated with the model. The main limitations of the model are associated with the approximation we adopted in the definition of the inundation scenario. Specifically, the presence of debris and suspended sediment is not directly considered; the flow depth was assumed to be the only forcing of the flow velocity; the flow direction was assumed to be always perpendicular to the shoreline. A more accurate scenario could be obtained following the completion of probabilistic assessment of sources. Lastly, the model is input data heavy and not all of the data required by the model will necessarily be available from LGA's. As such, considerable efforts must be invested to gathering field data on individual buildings. Future research might focus on other less intensive ways of gathering building attribute data such as via remote sensing techniques or national building databases.

Acknowledgements. We would like to thank the elected officials and professional staff of Randwick local government authority, Sydney for access to GIS data layer and building data to enable us to undertake the analysis at Maroubra. We also thank Maria Papthoma-Köhle and Stefan Reese for very helpful feedback on an earlier draft of the paper.

Edited by: S. Tinti

Reviewed by: M. Papathoma-Koehle and S. Reese

\section{References}

Bana e Costa, C. A. and Chargas, M. P.: An example of how to use MACBETH to build a quantitative value model based on qualitative value judgements, Eur. J. Oper. Res., 153, 323-331, 2004.

Bana e Costa, C. A., Da Silva, P. A., and Correia, F. N.: Multicriteria Evaluation of Flood Control Measures: The case of Ribeira do Livramento, Water Resour. Manag., 18, 263-283, 2004.

Bernard, B., Dengler, L., and Yim, S.: National Tsunami Research Plan: Report of a workshop sponsored by NSF/NOAA, NOAA Technical Memorandum OAR PMEL-133, 135 pp., http://nctr. pmel.noaa.gov/pubs.html, 2007.

Cutter, S. L., Boruff, B. J., and Lynn Shirley, W.: Social Vulnerability to Environmental Hazards, Soc. Sci. Quart., 84, 2, 242-261, 2003.

Dalrymple, R. A. and Kriebe, D. L.: Lessons in Engineering from the Tsunami in Thailand, The Bridge, 35, 4-13, 2005.

Dall'Osso, F. and Dominey-Howes, D.: A method for assessing the vulnerability of buildings to catastrophic (tsunami) flooding, unpublished Report, 137 pp., available at: http://www. sydneycoastalcouncils.com.au, 2009.

Dall'Osso, F., Gonella, G., Gabbianelli, G., Withycombe, G., and Dominey-Howes, D.: The vulnerability of buildings to tsunami in Sydney, Nat. Hazards Earth Syst. Sci., in review, 2009.

Dominey-Howes, D. and Papathoma, M.: Validating a Tsunami Vulnerability Assessment Model (the PTVA Model) Using Field Data from the 2004 Indian Ocean Tsunami, Nat. Hazards, 40, 113-136, 2007.
Dominey-Howes, D., Dunbar, P., Vernar, J., and PapathomaKöhle, M.: Estimating probable maximum loss from a Cascadia tsunami, Nat. Hazards, in press, 2009.

ECLAC (Economic Commission for Latin America and the Caribbean): Handbook for Estimating the Socio-economic and Environmental Effects of Disasters, 2003.

Fritz, M., Borrero, J. C., Synolakis, C. E., and Yoo, J.: 2004 Indian Ocean tsunami flow velocity measurements from survivors videos, Geophys. Res. Lett., 33, L24605, doi:10.1029/2006GL026784, 2006.

Ghobarah, A., Saatcioglu, M., and Nistor, I.: The impact of the 26 December 2004 earthquake and tsunami on structures and infrastructure, Eng. Struct., 28, 312-326, 2006.

Grundy, P., Thurairaja, A., and Walker, G.: Some Reflections on the Structural Engineering Aspects of Tsunami, in: Proceedings, Australian Earthquake Engineering Society, Albury, New South Wales, edited by: Lam, N. T. K., Wilson, J. L., and Butler, B., 7-1-7-4, 2005.

Matsutomi, H., Sakakiyama, T., Nugroho, S., and Matsuyama, M.: Aspects of inundated flow due to the 2004 Indian Ocean tsunami, Coast. Eng. J., 48, 2, 167-195, 2006.

Olivieri, E. and Santoro, M.: Estimation of urban structural flood damages: the case study of Palermo, Urban Water J., 2, $223-$ 234, 2000.

Olwig, M. F., Sorensen, M. K., Rasmussen, M. S., Danielsen, F., Selvams, V., Hansen, L. B., Nyborg, L., Vestergaard, K. B., Parish, F., and Karunaganas, V. M.: Using the remote sensing to assess the protective role of coastal woody vegetation against tsunami waves, Int. J. Remote Sens., 28, 13-14, 3153-3169, 2007.

Papathoma, M., Dominey-Howes, D., Zong, Y., and Smith, D.: Assessing tsunami vulnerability, an example from Herakleio, Crete, Nat. Hazards Earth Syst. Sci., 3, 377-389, 2003, http://www.nat-hazards-earth-syst-sci.net/3/377/2003/.

Papathoma, M. and Dominey-Howes, D.: Tsunami vulnerability assessment and its implications for coastal hazard analysis and disaster management planning, Gulf of Corinth, Greece, Nat. Hazards Earth Syst. Sci., 3, 733-747, 2003,

http://www.nat-hazards-earth-syst-sci.net/3/733/2003/.

Reese, S., Cousins, W. J., Power, W. L., Palmer, N. G., Tejakusuma, I. G., and Nugrahadi, S.: Tsunami vulnerability of buildings and people in South Java - field observations after the July 2006 Java tsunami, Nat. Hazards Earth Syst. Sci., 7, 573-589, 2007, http://www.nat-hazards-earth-syst-sci.net/7/573/2007/.

Rossetto, T., Peiris, N., Pomonis, A., Wilkinson, S. M., Del Re, D., Koo, R., and Gallocher, S.: The Indian Ocean tsunami of the December 26, 2004: observations in Sri Lanka and Thailand, Na. Hazards, 42, 105-124, 2007.

Saaty, T. L.: Axiomatic foundation of the Analytic Hierarchy Process, Manage. Sci., 32, 841-855, 1986.

Tanaka, N., Sasaki, Y., Mowjood, M. I. M., Jinadasa, K. B. S. N., and Homchuen, S.: Coastal vegetation structures and their functions in tsunami protection: experience of the recent Indian Ocean tsunami, Landsc. Ecol. Eng., 3, 33-45, 2007.

UNDP (United Nations Development Programme): Reducing disaster risk. A challenge for development. A Global Report, New York, 2004.

UNEP (United Nation Environment Program): After the Tsunami Rapid environmental assessment, 2005. 
F. Dall'Osso et al.: PTVA model for assessing the vulnerability of buildings

United Nations, Department of Humanitarian Affairs: Internationally Agreed Glossary of Basic Terms Related to Disaster Management, Geneva, Switzerland, 1992.

Warnitchai, P.: Lessons Learned from the 26 December 2004 Tsunami Disaster in Thailand, in: Proceedings of the 4th International Symposium on New Technologies for Urban Safety of Mega Cities in Asia, Singapore, 18-19 October, 2005. 